\title{
Mitochondrial Dysfunction in Congenital Nephrotic Syndrome
}

\author{
Marja-Liisa Solin, Sari Pitkänen, Jaan-Willem Taanman, and Harry Holthöfer \\ Haartman Institute (M-LS, HH), Division of Bacteriology and Immunology, University of Helsinki, and Department of \\ Dermatology (SP), Helsinki University Hospital, Helsinki, Finland; and Department of Neurological Sciences (J-WT), \\ Royal Free and University College Medical School, London, United Kingdom
}

SUMMARY: The molecular mechanisms maintaining the kidney glomerular filtration barrier remain poorly understood. Recent evidence suggests that mitochondrial dysfunction is a characteristic feature of kidney glomeruli in congenital nephrotic syndrome of the Finnish type (CNF). Here we searched for detailed functional evidence of mitochondrial lesion in CNF kidneys. We used histochemical and immunohistochemical methods, quantitative measurement of mitochondrial DNA, and superoxide production to characterize the mitochondrial function. The results unequivocally show down-regulation of mitochondria-encoded respiratory chain components, whereas the respective nuclearly encoded subunits were close to normal. These results give detailed evidence of distinct mitochondrial dysfunction and of the resulting abnormal production of reactive oxygen species in CNF and suggest a critical role for mitochondria in maintaining the glomerular permeability barrier. (Lab Invest 2000, 80:1227-1232).

$C$ ongenital nephrotic syndromes are rare renal diseases characterized by proteinuria, edema, and hypoproteinemia. They occur either in utero or manifest themselves soon after birth, thus differing from other nephrotic syndromes in childhood, which seldom occur before the age of one year. The bestcharacterized entities of idiopathic congenital nephrotic syndromes include congenital nephrotic syndrome of the Finnish type (CNF) and diffuse mesangial sclerosis (Hallman et al, 1967; Rapola, 1987). Both disorders present with proteinuria and edema without other primary symptoms but can be distinguished on the basis of renal histology, family history, and clinical appearance.

The pathophysiologic mechanisms of proteinuria remain, however, poorly understood. Because the glomerular cells and basement membranes together determine the filter that prevents passage into urine of plasma proteins and solutes in circulation (Kanwar et al, 1991; Kerjaschki, 1994; Rennke, 1994), it is assumed that the defect in CNF is specific for the glomerular structures. This makes CNF an exceptionally interesting model disease that can be used to determine the mechanisms maintaining the permselectivity of the glomerular filtration barrier.

Our search for genes involved in the pathogenesis of proteinuria with a differential display reverse transcriptase-polymerase chain reaction (RT-PCR) analysis of isolated CNF glomeruli recently revealed a major down-regulation of the mitochondrial respira-

Received February 28, 2000.

Address reprint requests to: Dr. Harry Holthöfer, The Haartman Institutel Bacteriology and Immunology. P.O.B. 21 (Haartmaninkatu 3), FIN00014 University of Helsinki, Helsinki, Finland. Fax: 3589191 26382, E-mail:Harry.Holthofer@Helsinki.Fi tory chain (Haltia et al, 1999). Further detailed studies revealed severely reduced transcript levels of the mitochondrial DNA (mtDNA)-encoded subunit I of enzyme complex IV of the mitochondrial respiratory chain (cytochrome-c oxidase [COX]) (Holthöfer et al, 1999). A decrease in the expression of other respiratory chain subunits encoded by the mitochondrial genome was also detected, whereas subunits encoded by the nuclear DNA remained at the level comparable to controls. These results strongly suggest a novel causative role for mitochondrial dysfunction in CNF and possibly in other proteinuric diseases.

To follow up the study of mitochondrial involvement, we have here investigated the mitochondrial function in CNF kidneys in detail and report a general decrease of mtDNA in kidney tissue together with decreased superoxide production in mitochondria of the renal cortex. An increase in the production of reactive oxygen species (ROS) has been demonstrated in experimental models of glomerular diseases (Kerjaschki, 1995), even before the onset of proteinuria (Solin M-L, Pitkänen S, Taanman J-W, and Holthöfer H, unpublished data). An increase of ROS correlates strongly with mitochondrial dysfunction and failure to maintain normal energy production, suggesting an important role for an intact energy balance and ROS in the pathogenesis of proteinuria.

\section{Results}

\section{Histochemistry, Immunohistochemistry, and Northern Blot Analysis}

To study the involvement of mitochondria in CNF at the protein and functional level, we have previously applied histochemical and immunohistochemical stainings for various respiratory chain complexes. 
Here we confirmed these findings by showing histochemically the down-regulation of succinate dehydrogenase (complex II) and cytochrome-c oxidase (complex IV) in cortical CNF kidney (Fig. 1) and by showing through immunohistochemistry (data not shown) the down-regulation of subunit COX I (mitochondrially encoded), whereas COX IV (nuclearly encoded) remained at the level of control tissues. Also, mRNA levels of COX subunits I and II, encoded by the mitochondrial genome, were down to approximately $25 \%$ of controls, whereas COX subunits IV and VIb, encoded by nuclear genome, showed only minor changes compared to controls (Fig. 2).

\section{Analysis of mtDNA}

Renal cortical mtDNA from patients with CNF was compared with mtDNA from control subjects on Southern blots. Blots hybridized with radioactively labeled probe for mtDNA showed that the size of mtDNA in the patients was comparable to controls (not shown). Blots cohybridized with the mitochondrial probe and with a probe for nuclear gene for 18S rRNA revealed, however, that mtDNA levels were markedly reduced in four of five patients as compared with controls (Fig 3). Quantification of the signals showed that, whereas mtDNA levels in $\mathrm{Pa}$ tient 1 were normal ( $97 \%$ of the average control values), mtDNA levels in Patients 2 to 5 were $17 \%$ to $40 \%$ of the average control values of age-matched controls.
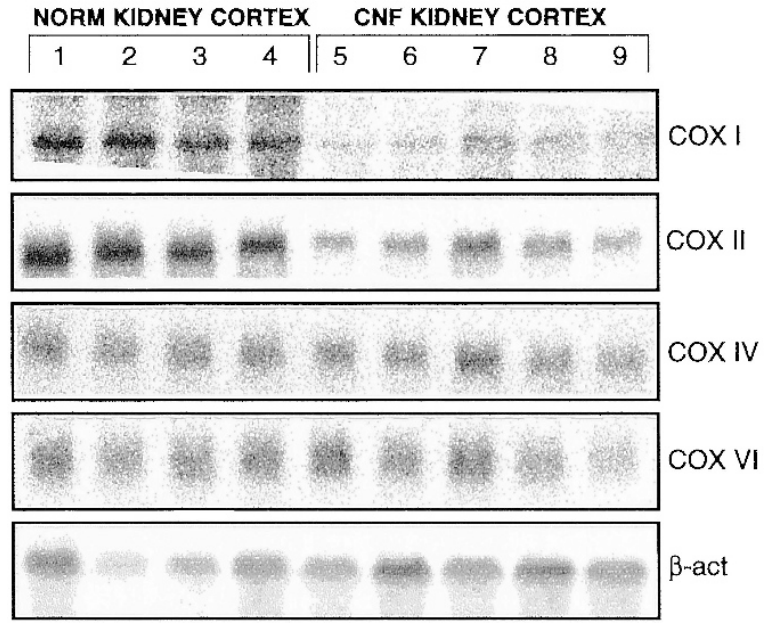

Figure 2.

Northern blotting of normal kidney cortex and CNF kidney cortex for COX subunits. The mitochondrially encoded subunits (COX I and II) are downregulated whereas the nuclearly encoded components (COX IV and COX VI) show similar levels in both CNF and control samples.

\section{Superoxide Production}

To assess the production of superoxide from the respiratory chain upon addition of NADH (Betts, 1986), mitochondria disrupted by freeze-thawing were incubated with the luminescent probe. Superoxide (SOX) production was markedly decreased in two of three CNF samples; SOX production of those two samples was $63 \%$ and $53 \%$ of normal kidney cortex samples, respectively. The third sample showed a SOX production similar to control kidney
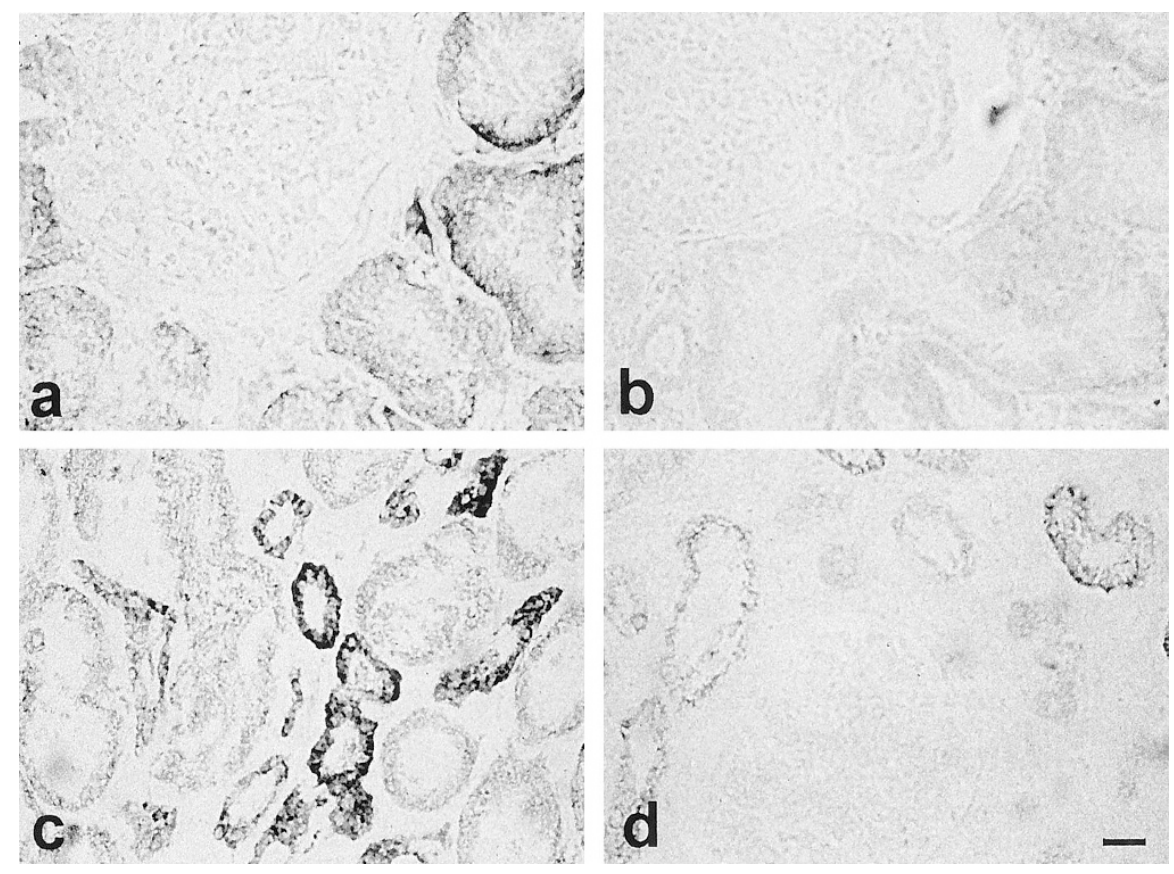

\section{Figure 1.}

Histochemical reactivity of normal kidney (a and $c$ ) and congenital nephrotic syndrome of the Finnish type (CNF) kidney ( $b$ and d) for succinate dehydrogenase (SDH) $(a$ and $b$ ) and cytochrome-c oxidase (COX) (c and d). Note the negligible reactivity in CNF for both SDH and COX. Magnification, $\times 320$. 


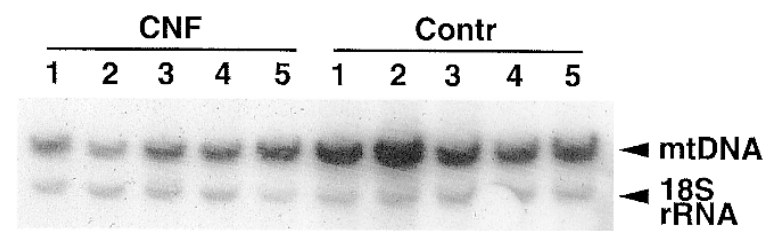

Figure 3.

Southern blot analysis with probe for mitochondrial DNA (mtDNA) shows considerably lower amounts of mtDNA in CNF kidneys compared with the controls. A probe for the nuclear gene 18S rRNA was used for evaluation of the amount of the total DNA loaded on each lane.

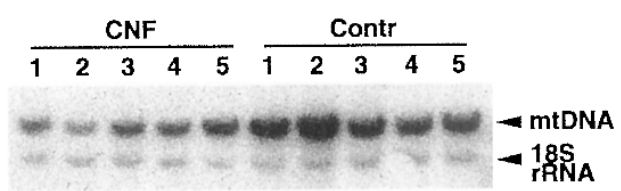

Figure 4.

Superoxide production in CNF and control kidney cortex shows distinct decrease of the luminescence in two of three CNF samples.

samples (Fig. 4). This sample was the only one showing a normal mtDNA level (see above).

\section{Enzyme Activities of the Respiratory Chain Complexes}

The activities of all enzyme complexes were decreased in cortical kidney tissues of CNF patients compared with normal kidney samples. The rotenonesensitive $\mathrm{NADH}$-cytochrome-c-reductase activities (complexes I and III), succinate cytochrome reductase activities (complexes II and III), and cytochrome-c oxidase activities (complex IV) were 49\%, 57\%, and $58 \%$ of the control values, respectively (Table 1 ).

\section{Discussion}

Our results have demonstrated that proteinuria in patients with CNF is associated with a mitochondrial failure within the kidney, but not in other tissues (Haltia et al, 1999; Holthöfer et al, 1999). Here we confirm and extend the previous findings and describe the mitochondrial dysfunction in detail. The biogenesis and function of mitochondria depend on complementation of both the nuclear and mitochondrial genomes (Wallace et al, 1998). The human mtDNA, which is inherited through the maternal line, contains a limited number of genes that are all involved in the synthesis of the mitochondrial respiratory chain components (Taanman et al, 1997). The vast majority of polypeptides needed for the biogenesis of the organelle are, however, encoded by the nuclear genome (Taanman et al, 1997). A finely regulated assembly of the nucleusencoded components, together with the ones encoded by the mitochondrial DNA, is essential for proper functionality, including ATP production and control of the shunt pathway leading to ROS production (Halliwell, 1991). Our results suggest that although the basic defect of CNF involves a recently characterized autosomal gene in chromosome 19 (Kestila et al, 1998; Mannikko et al, 1995), its presently unknown downstream effects and functions may also directly involve regulation of local mitochondrial functions. Alternatively, a two-hit defect, with both nuclear and mitochondrial involvement, as described, eg, for autosomal dominant progressive external ophthalmoplegia (Kaukonen et al, 1996; Suomalainen et al, 1997), has to be considered.

Hallman et al (1956) first characterized the clinical features of CNF. Further studies by Norio (1966) revealed the inheritance pattern as autosomal recessive. The incidence of CNF is 1:8000 live births in Finland. Earlier, this disease led to death within the first 6 months of life because of an uncontrolled loss of circulating plasma proteins into urine. Since 1984, a new treatment protocol has emerged, which includes early nephrectomy, followed by dialysis, and then renal transplantation (Mahan et al, 1984). This treatment seems to cure all symptoms and, notably, without later manifestations in other organ systems (Holmberg et al, 1995). The success of renal transplantation emphasizes the tissue-specific character of the disease.

Although the presenting symptom in CNF is the uncontrolled proteinuria, patients with symptoms from the muscular, cardiac, and central nervous systems have also been reported (Mannikko et al, 1995). Involvement of these organs is the characteristic finding in mitochondrial disorders (Johns, 1995).

Kestilä et al (1998) recently identified the new gene NPHS1, encoding a mutated transmembrane protein nephrin, in patients with CNF. According to their results, nephrin is expressed only in kidney glomeruli,

Table 1. Respiratory Chain Enzyme Activities

\begin{tabular}{|c|c|c|c|c|c|c|}
\hline & \multicolumn{2}{|c|}{$\begin{array}{l}\text { Complexes I and III } \\
\text { (U/mg protein) }\end{array}$} & \multicolumn{2}{|c|}{$\begin{array}{l}\text { Complexes II and III } \\
\text { (U/mg protein) }\end{array}$} & \multicolumn{2}{|c|}{$\begin{array}{l}\text { Complex IV } \\
\text { (U/mg protein) }\end{array}$} \\
\hline & Mean & $\pm S D$ & Mean & $\pm \mathrm{SD}$ & Mean & $\pm S D$ \\
\hline CNF 1 & 85,6 & 7,9 & 64,2 & 0,8 & 38,2 & 1,2 \\
\hline CNF 2 & 74,4 & 5,1 & 58,7 & 2,4 & 33,8 & 0,0 \\
\hline CNF 3 & 98,1 & 6,0 & 80,2 & 2,4 & 36,2 & 2,3 \\
\hline Control 1 & 170,0 & 18,2 & 131,2 & 1,0 & 66,4 & 11,0 \\
\hline Control 2 & 138,7 & 7,7 & 111,2 & 1,3 & 58,5 & 2,7 \\
\hline Control 3 & 219,5 & 12,6 & 112,1 & 3,3 & \multicolumn{2}{|c|}{ ND } \\
\hline
\end{tabular}

SD, standard deviation; CNF, congenital nephrotic syndrome of the Finnish type; ND, not determined. 
but virtually nothing is presently known of its exact functions and expression in other tissues. Interestingly, the vicinity of the NPHS1 locus in the long arm of chromosome 19 contains several genes crucial for the mitochondrial biogenesis, including the genes for COX Vlb (Taanman et al, 1991), ATPase (Song et al, 1992), and PHGPx (Kelner et al, 1998).

The mitochondrial respiratory chain produces cellular energy mainly through oxidative phosphorylation. Abnormal electron transfer in the respiratory chain not only diminishes energy production but also leads acutely to an increased production of ROS, including the superoxide, hydroxide, and hypochloric acid anions (Wallace et al, 1998). These compounds are rapidly reactive, indiscriminately damaging to proteins, lipids, and nucleic acids (Halliwell, 1991). Under normal circumstances, cellular antioxidants protect the cell from damage by trapping ROS (Wallace, 1998). Increased ROS production and evidence of free radical damage, particularly in the form of lipid peroxidation, are associated with many diseases (Halliwell, 1991). Interestingly, the kidney glomerulus appears particularly vulnerable to ROS and lipoperoxide damage. This may be due to a cell-type, specific antioxidant capacity. Glomerular podocytes, however, may also show dysregulated production of ROS, as extensively shown by Neale et al, $(1993,1994)$. This indirectly suggests that the maintenance of an oxidationantioxidation balance may be needed, eg, for an intact intracellular signaling milieu (Finkel, 1998).

The decrease of superoxide production, as found here, may reflect an exhausted capacity for ROS production in CNF mitochondria or simply the fact that the low level of mtDNA is unable to provide the machinery for ROS or energy production, much like in the previously identified mitochondrial depletion syndromes (Taanman et al, 1996). Whether the cell-type specific net effect is an altered cellular signaling remains to be studied in detail. Interestingly, in many forms of human and experimental glomerulonephritis, including CNF (Holthöfer et al, 1999), an increase of local lipoperoxides can be found.

Here we obtained direct evidence of the decrease of mitochondrial functions in CNF samples. It should be noted that we have previously found abnormal splitting of nidogen (Ljungberg et al, 1996), a typical defect found in ROS damage in vivo and in vitro (Riedle and Kerjaschki, 1997). Similar changes in mitochondrial functions have been previously observed in a mitochondrial depletion syndrome (Taanman et al, 1997). Interestingly, although one of the CNF samples studied failed to show major changes in superoxide production, it presented with a major decrease in complex IV and a decrease of mtDNA content of $30 \%$ compared with controls. Thus, variability in the mitochondrial involvement may be found among patients with CNF, possibly reflecting the genetic heterogeneity of the mutations found in the causative NPHS1 (Kestilä et al, 1998; Lenkkeri et al, 1999).

The present results show a major decrease of mtDNA in the kidney cortex of patients with CNF. The observed decrease of subsequent superoxide pro- duction supports the following hypothesis: a primary or secondary damage of mitochondria leads to a decrease in local energy and modification of ROS generation. In tissues with defective antioxidant defense, as shown in glomeruli, this may result in severe functional consequences.

\section{Materials and Methods}

\section{Kidney Samples}

Cadaver kidneys unsuitable for transplantation for vascular-anatomic reasons were used as normal human kidney tissues (Department of Surgery, Helsinki University Hospital, Helsinki, Finland). The ages of the donors $(n=4)$ were $3,12,37$, and 48 years, but in the Southern blot experiment, five pediatric kidneys were used as controls. Kidney samples from patients with CNF $(n=5)$ were obtained during therapeutic nephrectomies performed with affected children, aged 6 to 16 months, according to established treatment protocol (Children's Hospital, University of Helsinki) (Holmberg et al, 1995). Immediately after removal of the kidneys, cortical tissues were mechanically separated from medulla and prepared for isolation of glomeruli or snap-frozen in liquid nitrogen and stored at $-70^{\circ} \mathrm{C}$ until used for the extraction of cortical RNA. All procedures used in this study were approved by the Ethical Committees of the respective departments of the Helsinki University Central Hospital.

\section{Histochemistry}

Histochemical methods for respiratory chain complexes II (succinate dehydrogenase) (Bancroft, 1975) and IV (COX) (Seligman et al, 1968) were used. Fresh cryostat sections of $5 \mu \mathrm{m}$ were incubated with their specific substrate solutions, and brown insoluble granular deposits were produced at sites of enzymatic activity.

\section{Northern Blot Analysis}

Total RNA from the five CNF and four normal human cortex samples was isolated using the guanidineisothiocyanate/CsCl method (Chirgwin et al, 1979), electrophoresed (30 $\mu \mathrm{g}$ RNA/lane) through 1.0\% agarose gels containing $2.2 \mathrm{M}$ formaldehyde, and transferred to nylon membranes (Hybond-N; Amersham, Buckinghamshire, United Kingdom) (Sambrook et al, 1989). Membranes were UV cross-linked (Stratalinker; Stratagene, La Jolla, California) and prehybridized in $5 \times$ SSC ( $1 \times$ SSC: $150 \mathrm{~mm} \mathrm{NaCl,} 15 \mathrm{~mm}$ Na-citrate); $50 \%$ formamide; $5 \times$ Denhardt's reagent; $0.1 \%$ SDS; 50 mм Na-phosphate buffer, $\mathrm{pH}$ 6.5; and $250 \mu \mathrm{g} / \mathrm{ml}$ salmon sperm DNA (Sigma Chemical Company, St. Louis, Missouri) at $42^{\circ} \mathrm{C}$. Probes were radioactively labeled by incorporation of $\left[\alpha^{32} \mathrm{P}\right]$ dCTP $(>3000 \mathrm{Ci} /$ mmol; Dupont NEN, Boston, Massachusetts), using the Random Primer labeling kit (Boehringer, Mannheim, Germany), and hybridized to blots in prehybridization buffer at $42^{\circ} \mathrm{C}$ for 16 hours. Blots were subsequently washed three times in $1 \times$ SSC, $0.1 \%$ SDS, 
at $65^{\circ} \mathrm{C}$. To assess the total RNA content and integrity of the analyzed samples, blots were rehybridized with a human $\beta$-actin probe. For autoradiography, filters were exposed to an imaging plate (Fuji Photo Film Company, Tokyo, Japan), and mRNA signals were quantified using MacBAS software (Fuji Photo Film Company).

\section{Southern Blot Analysis}

Total genomic DNA was extracted from the five CNF and five pediatric cadaver kidney cortex tissue samples with the method outlined by Maniatis (Sambrook et al, 1989). Similar amounts $(\approx 2 \mu \mathrm{g})$ of DNA were digested with Pvull, electrophoresed through $0.8 \%$ agarose gel, and blotted onto Hybond-N membrane (Amersham) as recommended by the supplier. Blots were hybridized with two probes: a cloned $5.8-\mathrm{kb}$ EcoRl fragment of the gene coding for 18S rRNA (Cheng et al, 1994) and the entire mtDNA generated by long-range PCR amplification. Probes were labeled with $\left[\alpha^{32} \mathrm{P}\right]$ dCTP using the Radiprime Random Prime Labeling System (Amersham). Membranes were prehybridized and hybridized as suggested by the manufacturer and exposed to $\beta$-Max film (Amersham). Bound probe was quantified by volume integration on a Photo Imager using ImageQuant software (Molecular Dynamics, Sunnyvale, California). Signals of mtDNA are expressed as a ratio to the corresponding nuclear DNA signal.

\section{Isolation of Mitochondria}

Mitochondria were isolated from liquid $\mathrm{N}_{2}$ frozen kidney cortex samples by homogenizing the tissue in a buffer of $250 \mathrm{~mm}$ sucrose, $2 \mathrm{~mm}$ EDTA, and $10 \mathrm{~mm}$ Tris- $\mathrm{Cl}, \mathrm{pH}$ 7.4. The homogenate was passed through a tissue press and centrifuged at $1000 \times g$. The resulting supernatant was centrifuged at $10,000 \times g$ to sediment the mitochondria. Citrate synthase activity was measured by the method of Srere et al (1963).

\section{Superoxide Production in Isolated Mitochondria}

Lucigenin (N, N'-dimethyl-9,9'-biacridinium dinitrate, Sigma) was used as chemiluminescent probe to quantify superoxide production monitored as emitted light by a luminometer (Luminometer model 1253; BioOrbit, Turku, Finland) according the method described by Betts (1986). Briefly, frozen-thawed mitochondria isolated from cortex samples of three CNF and three control kidneys were added to $10 \mathrm{~mm} \mathrm{~K}_{2} \mathrm{HPO}_{4}, \mathrm{pH}$ 10.5 , and the cuvette was placed into the counter. Background was subtracted and counting was initiated. NADH $(50 \mu \mathrm{g} / 10 \mu \mathrm{l})$ was added to the cuvette as the substrate to initiate respiratory chain electron transport. NADH is reduced by diaphorase in fibroblast mitochondria preparations. NADH functions as a reducing agent via diaphorase in fibroblast mitochondria preparations for the lucigenin probe, which is a prerequisite for the reduction of lucigenin with superoxide radical (Faulkner and Fridovich, 1993). The luminometer was set to count for 30 seconds at $25^{\circ} \mathrm{C}$.
Superoxide production was measured with replicate samples twice independently. Results are expressed as $\mathrm{U} / \mathrm{mg}$ of protein.

\section{Respiratory-Chain Enzyme Activities}

Mitochondria were isolated and activities of respiratory-chain enzymes were determined for CNF and control kidneys as triplicate samples. The rotenone-sensitive $\mathrm{NADH}$-cytochrome c reductase activity (complexes I and III) was measured by the method of Moreadith et al (1984). COX activity (complex IV) was measured as described by Glerum et al (1988), and succinate cytochrome reductase activity (complexes II and III) by the method of Fujii et al (1990). The protein concentrations were determined by the method of Lowry et al (1951). Results are expressed as $\mathrm{U} / \mathrm{mg}$ of protein.

\section{References}

Bancroft J (1975). Histochemical techniques, 2nd ed. Boston: Butterworths, 280-285.

Betts WH (1986). Detecting radicals by chemiluminescence. In: Greenwald RA, editor. Handbook of methods for oxygen radical research. Boca Raton: CRC Press, 197-201.

Cheng S, Higuchi R, and Stoneking M (1994). Complete mitochondrial genome amplification (letter). Nat Genet 7:350-351.

Chirgwin JM, Przybyla AE, MacDonald RJ, and Rutter WJ (1979). Isolation of biologically active ribonucleic acid from sources enriched in ribonuclease. Biochemistry 18:52945299.

Faulkner K and Fridovich I (1993). Luminol and lucigenin as detectors for $\mathrm{O}_{2}$. Free Radic Biol Med 15:447-451.

Finkel T (1998). Oxygen radicals and signaling. Curr Opin Cell Biol 10:248-253.

Fujii T, Ito M, Okuno T, Mutoh K, Nishikomori R, Mikawa H (1990). Complex I (reduced nicotinamide-adenine dinucleotide-coenzyme $Q$ reductase) deficiency in two patients with probable Leigh syndrome. J Pediatr 116:84-87.

Glerum DM, Yanamura W, Capaldi RA, and Robinson BH (1988). Characterization of cytochrome-c oxidase mutants in human fibroblasts. FEBS Lett 236:100-104.

Halliwell B (1991). Reactive oxygen species in living systems: Source, biochemistry, and role in human disease. Am J Med 91:14S-22S.

Hallman N, Hjelt L, and Ahvenainen EK (1956). Nephrotic syndrome in newborn and young infants. Ann Paediatr Fenn 2:227-241.

Hallman N, Norio R, and Kouvalainen K (1967). Main features of the congenital nephrotic syndrome. Acta Paediatr Scand 172:75-78.

Haltia A, Solin M, Luimula $P$, Kretzler $M$, and Holthöfer $H$ (1999). mRNA differential display analysis of nephrotic kidney glomeruli. Exp Nephrol 7:52-58.

Holmberg C, Antikainen M, Ronnholm K, Ala-Houhala M, and Jalanko H (1995). Management of congenital nephrotic syndrome of the Finnish type. Pediatr Nephrol 9:87-93. 
Holthöfer H, Kretzler M, Haltia A, Solin ML, Taanman JW, Schagger H, Kriz W, Kerjaschki D, and Schlondorff D (1999). Altered gene expression and functions of mitochondria in human nephrotic syndrome. FASEB J 13:523-532.

Johns DR (1995). Mitochondrial DNA and disease. N Engl $\mathrm{J}$ Med 333:638-644.

Kanwar YS, Liu ZZ, Kashihara N, and Wallner El (1991). Current status of the structural and functional basis of glomerular filtration and proteinuria. Semin Nephrol 11:390413.

Kaukonen JA, Amati P, Suomalainen A, Rotig A, Piscaglia MG, Salvi F, Weissenbach J, Fratta G, Comi G, Peltonen L, and Zeviani M (1996). An autosomal locus predisposing to multiple deletions of mtDNA on chromosome 3p. Am J Hum Genet 58:763-769.

Kelner MJ and Montoya MA (1998). Structural organization of the human selenium-dependent phospholipid hydroperoxide glutathione peroxidase gene (GPX4): Chromosomal localization to 19p13.3. Biochem Biophys Res Commun 249:53-55.

Kerjaschki D (1994). Dysfunctions of cell biological mechanisms of visceral epithelial cell (podocytes) in glomerular diseases. Kidney Int 45:300-313.

Kerjaschki D (1995). Epitopes and radicals: Early events in glomerular injury in membranous nephropathy (editorial). Exp Nephrol 3:1-8.

Kestilä M, Lenkkeri U, Mannikko M, Lamerdin J, McCready P, Putaala H, Ruotsalainen V, Morita T, Nissinen M, Herva R, Kashtan CE, Peltonen L, Holmberg C, Olsen A, and Tryggvason K (1998). Positionally cloned gene for a novel glomerular protein, nephrin, is mutated in congenital nephrotic syndrome. Mol Cell 1:575-582.

Lenkkeri U, Männikö M, McReady P, Lamerdin J, Gribouval O, Niaudet PM, Antignac C, Kashtan CC, Holmberg C, Olsen A, Kestilä M, Tryggvason K (1999). Structure of the gene for congenital nephrotic syndrome of the finnish type (CNF) and characterization of mutations. Am J Hum Genet 64:51-61.

Ljungberg $\mathrm{P}$, Haltia A, Kuusela $\mathrm{P}$, Jalanko $\mathrm{H}$, Holmberg $\mathrm{C}$, and Holthöfer $\mathrm{H}$ (1996). Noncollagenous matrix components of glomeruli in congenital nephrotic syndrome of the Finnish type: Evidence of abnormal splitting of nidogen. Exp Nephrol 4:286-294.

Lowry OH, Rosenbroug NJ, Farr AL, and Randall RJ (1951). Protein measurement with the Folin phenol reagent. $\mathrm{J}$ Biol Chem 193:265-275.

Mahan JD, Mauer SM, Sibley RK, and Vernier RL (1984). Congenital nephrotic syndrome: Evolution of medical management and results of renal transplantation. J Pediatr 105: $549-557$.

Mannikko M, Kestila M, Holmberg C, Norio R, Ryynanen M, Olsen A, Peltonen L, and Tryggvason K (1995). Fine mapping and haplotype analysis of the locus for congenital nephrotic syndrome on chromosome 19q13.1. Am J Hum Genet 57: 1377-1383.

Moreadith RW, Batshaw ML, Ohnishi T, Kerr D, Knowx B, Jackson D, Hruba R, Olson J, Reynafarje B, and Lehninger AL (1984). Deficiency of the iron-sulfur clusters of mitochondrial reduced nicotinamide-adenine dinucleotide-ubiquinone oxidoreductase (complex I) in infant congenital lactic acidosis. J Clin Invest 74:685-697.
Neale TJ, Ojha PP, Exner M, Poczewski H, Ruger B, Witztum JL, Davis P, and Kerjaschki D (1994). Proteinuria in passive Heymann nephritis is associated with lipid peroxidation and formation of adducts on type IV collagen. J Clin Invest 94:1577-1584.

Neale TJ, Ullrich R, Ojha P, Poczewski H, Verhoeven AJ, and Kerjaschki D (1993). Reactive oxygen species and neutrophil respiratory burst cytochrome b558 are produced by kidney glomerular cells in passive Heymann nephritis. Proc Natl Acad Sci USA 90:3645-3649.

Norio R (1966). Heredity in the congenital nephrotic syndrome. A genetic study of 57 Finnish families with a review of reported cases. Ann Paediatr Fenn 12:1-94.

Rapola J (1987). Congenital nephrotic syndrome. Pediatr Nephrol 1:441-446.

Rennke HG (1994). How does glomerular epithelial cell injury contribute to progressive glomerular damage? Kidney Int 45:S58-S63.

Riedle B and Kerjaschki D (1997). Reactive oxygen species cause direct damage of Engelbreth-Holm-Swarm matrix. Am J Pathol 151:215-231.

Sambrook J, Fritsch EF, and Maniatis T (1989). Molecular cloning: A laboratory manual. Cold Spring Harbor: Cold Spring Harbor Laboratory Press.

Seligman AM, Karnovsky MJ, Wasserkrug HL, and Hanker JS (1968). Nondroplet ultrastructural demonstration of cytochrome oxidase activity with a polymerizing osmiophilic reagent, diaminobenzidine (DAB). J Cell Biol 38:1-14.

Song I, Yamada T, Trent JM (1992). Mapping of the gene encoding the alpha-subunit of the human $\mathrm{H}(+), \mathrm{K}(+)$-ATPase to chromosome 19q13.1 by fluorescent in situ hybridization. Genomics 14:547-548.

Srere PA, Brazil H, and Gonen L (1963). The citrate condensing enzyme of pigeon breast muscle and moth flight muscle. Acta Chem Scand 17:5129-5134.

Suomalainen A, Majander A, Wallin M, Setala K, Kontula K, Leinonen H, Salmi T, Paetau A, Haltia M, Valanne L, Lonnqvist J, Peltonen L, and Somer H (1997). Autosomal dominant progressive external ophthalmoplegia with multiple deletions of mtDNA: Clinical, biochemical, and molecular genetic features of the $10 \mathrm{q}$-linked disease. Neurology 48: 1244-1253.

Taanman JW, Bodnar AG, Cooper JM, Morris AA, Clayton PT, Leonard JV, and Schapira AH (1997). Molecular mechanisms in mitochondrial DNA depletion syndrome. Hum Mol Genet 6:935-942.

Taanman JW, Burton MD, Marusich MF, Kennaway NG, and Capaldi RA (1996). Subunit specific monoclonal antibodies show different steady-state levels of various cytochrome-c oxidase subunits in chronic progressive external ophthalmoplegia. Biochim Biophys Acta 1315:199-207.

Taanman JW, van der Veen AY, Schrage C, de Vries $\mathrm{H}$, and Buys CH (1991). Assignment of the gene coding for human cytochrome c oxidase subunit Vlb to chromosome 19, band q13.1, by fluorescence in situ hybridisation. Hum Genet 87:325-327.

Wallace DC, Brown MD, Melov S, Graham B, and Lott M (1998). Mitochondrial biology, degenerative diseases, and aging. Biofactors 7:187-190. 